\title{
Do infants with Down syndrome show an early receptive language advantage?
}

Article

Accepted Version

Mason-Apps, E., Stojanovik, V., Houston-Price, C., Seager, E. and Buckley, S. (2020) Do infants with Down syndrome show an early receptive language advantage? Journal of Speech, Language and Hearing Research, 63 (2). pp. 585-598. ISSN 1558-9102 doi: https://doi.org/10.1044/2019_JSLHR-19-00157 Available at https://centaur.reading.ac.uk/87401/

It is advisable to refer to the publisher's version if you intend to cite from the work. See Guidance on citing.

To link to this article DOI: http://dx.doi.org/10.1044/2019_JSLHR-19-00157

Publisher: ASHA

All outputs in CentAUR are protected by Intellectual Property Rights law, including copyright law. Copyright and IPR is retained by the creators or other copyright holders. Terms and conditions for use of this material are defined in the End User Agreement.

\section{www.reading.ac.uk/centaur}

\section{CentAUR}

Central Archive at the University of Reading 
Reading's research outputs online 


\section{Abstract}

\section{Purpose}

$4 \quad$ The study explored longitudinally the course of vocabulary and general language

5 development in a group of infants with Down syndrome (DS) compared to a group of

6 typically-developing (TD) infants matched on non-verbal mental ability (NVMA).

\section{$7 \quad$ Method}

8 We compared the vocabulary and general language trajectories of the two groups in two

9 ways: a) at three time points during a 12 month period, and b) at 2 time points when the

10 groups had made equal progress in non-verbal mental ability (a period of 6 months for the TD

11 infants, versus 12 months for the infants with DS).

\section{Results}

13 The TD group had overtaken the DS group on all general language and vocabulary measures by the end of the 12-month period. However, expressive communication and expressive vocabulary were developing at the same rate and level in the two groups when examined over a period in which the two groups were matched in gains in non-verbal mental ability.

17 Furthermore, the infants with DS showed a receptive language advantage over the TD group; this group's auditory comprehension and receptive vocabulary scores were superior to those of the TD group at both time points when non-verbal mental ability was accounted for.

\section{Conclusion}

21 The results shed light on the widely reported discrepancy between expressive and receptive

22 language in individuals with DS. Although infants with DS appear to be developing language skills more slowly than chronological age TD peers, when NVMA is taken into account, 
infants with DS do not have expressive language delays and they seem to show a receptive language advantage.

\section{Introduction}

Down syndrome (DS) is the most common genetic cause of intellectual disability (Martin, Klusek, Estigarribia, \& Roberts, 2009) with prevalence estimates of 1 in 691 live births (Parker et al., 2010). It results from partial or complete duplication of chromosome 21 (Epstein, 1986). Characteristic features include a flat broad face, flat nasal bridge, and flat facial profile, narrow auditory canals, a small oral cavity, a relatively large tongue, and low muscle tone of the lips and tongue (Martin et al., 2009). Individuals with DS typically have an IQ of between 30 and 70 (average 50).

Language acquisition is delayed in DS (Roberts, Price \& Malkin, 2007). Infants with DS have been reported to produce their first words at approximately 21 months (StoelGammon, 2001), compared to 12 months of age for TD infants (Tomasello, 2003). First words are acquired in line with general cognitive ability (Miller, 1999). An asynchrony between receptive and expressive vocabulary has been reported for 4- to 7- year old children with DS (Caselli et al., 1998), which is similar to typically developing children (Caselli et al., 1995 ) in that expressive vocabulary lagged behind receptive. Expressive language in DS can be progressively delayed relative to receptive language and general non-verbal skills (Abbeduto, Warren, \& Conners, 2007; Chapman \& Hesketh, 2000).

In adolescents and adults with DS, receptive vocabulary is usually reported as a relative strength (Abbeduto, Warren \& Conners, 2007) and generally in line with non-verbal mental age. Importantly, receptive vocabulary has sometimes been reported as exceeding general non-verbal abilities (Abbeduto et al., 2007; Naess et al., 2011). 
It used to be believed that the majority of children with DS under 5 years of age have

a linguistic profile characterised by receptive language skills that are in line with non-verbal mental age, and expressive language skills that are lower than expected for non-verbal mental age (Miller, 1999). Recent studies show that the picture is more complex and there are mixed findings especially when using longitudinal frameworks. Galeote et al., (2011), using a Spanish adaptation of the MacArthur-Bates CDI, reported significantly larger receptive vocabularies for 186 children with DS (aged 11 to 71 months) compared to TD children matched for mental age, while expressive vocabularies were in line with their non-verbal mental age. This study was cross-sectional and hence only provides a snapshot of development. There is a paucity of longitudinal studies and few of the existing ones have focused on language acquisition in the first three years of life with some studies focusing solely on vocabulary acquisition and others on general language acquisition. These are reviewed below.

\section{Longitudinal studies of vocabulary development: receptive and expressive}

Focusing exclusively on early acquisition of object names, Cardoso-Martins, Mervis, and Mervis (1985) followed longitudinally 6 children with DS aged 17-19 month at the start of the study, and compared them to 6 typically developing children aged 9 months at the start of the study. After an initial lack of difference between the two groups, the acquisition of object names in the DS group (comprehension and production) was reported to start to lag behind their general non-verbal cognitive skills suggesting that vocabulary acquisition develops at a slower pace than level of general cognitive abilities from an early age. Due to the very small sample size $(n=6)$, the findings should be taken cautiously, however. A more recent study, using the Italian version of the MacArthur-Bates CDI with 18 children with DS aged between 2 and 3, Zampini and D'Odorico (2013) also reported that expressive vocabulary lags behind general cognitive development, with the main changes in vocabulary 
development occurring at 36 months chronological age, when individual differences become more prominent. Focusing exclusively on expressive vocabulary, Te Kaat van den Os, Volman, Jongmans, and Lauteslager (2017) followed longitudinally 26 children with DS aged between 18 and 24 months at the start of the study. Parents completed the Lexi questionnaire monthly over a period of 18 months which measures expressive vocabulary and gesture use in toddlers (Schlichting \& Lutje Spelberg, 2002, cited in Te Kaat van den Os et al., 2017). Wide individual variation was reported as in Zampini and D'Odorico's study, but general cognitive abilities were related to children's expressive vocabulary growth. Specifically, the children who made marginal progress with their vocabulary development had significantly lower general cognitive skills than the children who had a more significant growth in their vocabulary.

Focusing solely on receptive vocabulary, Cuskelly, Povey and Jobling (2016) investigated receptive vocabulary development from 2 years 9 months to mid adulthood in 206 individuals with DS using the Peabody Picture Vocabulary Scale (PPVT). Receptive vocabulary increased up to around 20 years of age and then started to decline. The rate of receptive vocabulary development in childhood and adolescence in DS was reported to be slower than in typically developing children but there was a positive association between receptive vocabulary and general non-verbal ability.

In summary, the few longitudinal studies on vocabulary development suggest that, on the whole, and if we weight the findings of studies with a larger number of participants more heavily (Te Kaat van den Os et al., 2017 \& Cuskelly et al., 2016), vocabulary development in children with DS is slower in the early stages of acquisition compared to typical language development and appears to be related to general cognitive abilities.

\section{Longitudinal studies of general language development: expressive language}


97

development beyond vocabulary acquisition (Levy \& Eilam, 2013; Oliver \& Buckley, 1994).

Oliver and Buckley (1994), using parental report, followed the development of vocabulary acquisition of nine children with DS (aged between 1 and 4 years) until they reached a vocabulary of 10 words, which children achieved between the ages of 19 and 38 months. Two word combinations emerged between 25 and 52 months (mean age of around 36 months). Children with DS had acquired a similar number of words to TD children at the point when they started producing two word utterances. Non-verbal mental ages were not reported, hence we do not know if there was any relationship between children's language development and their non-verbal mental ability.

A more recent study by Levy and Eilam (2013) followed longitudinally 9 children with DS (mean age of 3 years 10 months at study entry) using a naturalistic data collection method. The children with DS were significantly delayed in entering the two-word combinations stage compared to the TD children of a similar non-verbal mental age. Specifically, while the TD children entered this stage at approximately 22 months of age, the children with DS entered this stage at approximately 55 months of age. Although the children with DS showed a typical trajectory of development over one calendar year with regard to language structure, there was atypical age of onset of two-word combinations and slower developmental pace. This deviation from typical timing was taken to suggest atypical grammatical development in children with DS. In addition, general cognitive ability was not related to the children's language status.

In summary, these two studies focus on expressive language only. Both agree that children with DS start producing two word combinations later than typically developing children (between 36 and 55 months of age). Moreover, Levy and Eilam (2013) propose that 
grammatical development follows an atypical trajectory in children with DS, reflected in both a later onset and slower pace of development.

\section{Theoretical considerations}

The question of whether the developmental profiles of children with neurodevelopmental disorders can be described as 'typical' is a matter of considerable debate. It is unlikely that children with neurodevelopmental disorders, such as Down syndrome, would follow a typical developmental trajectory because genetic abnormalities very likely affect developmental pathways, and the adult phenotype is the product of an emergent developmental process (Karmiloff-Smith, 1998; Karmiloff-Smith, 2009; D’Souza, D’Souza \& Karmiloff-Smith, 2017). Furthermore "tiny variations in the initial state" can become magnified into large domain-specific differences as a result of development (Karmiloff-Smith 1998, p. 390). Developmental timing is one parameter that influences typical development. For example, in the case of children with Down syndrome, small differences in the timing of the onset of two-word combinations (which appear in children in DS 12-24 months later than in TD children) can lead to a delay in the children's ability to understand and produce SVO structures, which in turn can lead children to lag further behind peers in accessing relevant information in the education context. Thus, what appear to be small variations in timing in early development can compound over time, leading to a profile of severely impaired expressive language later on in adolescence and adulthood.

\section{Aims of current study}

Previous studies on language development of infants and children with DS have focused exclusively on either vocabulary, or general expressive language development. Although some studies have compared expressive and receptive vocabulary in individuals with DS, no study to our knowledge has explored the trajectories of general expressive and 
receptive language skills (i.e. expressive and receptive communication which may or may not include grammar) and expressive and receptive vocabulary, at the early stages of language development in DS and in relation to non-verbal mental ability development. Thus, unlike most previous longitudinal studies, our study captures both the acquisition of vocabulary, and

general language skills beyond single word production and comprehension in the same children, providing a more complete picture of this group of children's early language comprehension and production. It is also crucial to consider language development in infancy to understand development as it unfolds, as we cannot assume that the adult phenotype also applies to the start state of development (Karmiloff-Smith, 1998). In addition, we want to understand language within the broader context of children's general cognitive skills. The purpose of the current study is therefore twofold:

1) to establish how expressive and receptive vocabulary, and expressive and receptive general language abilities of a group of infants with DS develop over the course of 12 months in the first 3 years of life, and how their developmental trajectories compare to the language development of TD children. The two groups are compared at 3 different time points and they have equal non-verbal mental ability at Time Point 1 only (the TD group develops faster than the DS group and by Time Point 2 the TD group has higher non-verbal ability than the DS group). General language abilities are measured using a standardised assessment (the PreSchool Language Scales-4) with two components: auditory comprehension (i.e. general understanding of language) and expressive communication (general language production not restricted to grammar)

2) given that the non-verbal abilities of the TD group develop faster than the $\mathrm{DS}$ group, which may explain the differences in language profiles at later time points, the second aim is to establish how language development of infants with DS compares to that of TD infants 
over a period of 12 months in which the groups have made similar progress in non-verbal mental ability. The two groups are compared at two time points and they have equal nonverbal ability at the two time points.

\section{Method}

\subsection{Ethical approval}

The current study was approved by the University of Reading's Research Ethics Committee and given favourable ethical opinion. TD infants were recruited from the Child Development Database at the University of Reading. This database holds the details of infants and children whose parents have consented to being contacted about studies taking place within the University of Reading. Parents of TD infants were telephoned and asked if they would be willing to take part in the study. If they were interested, then they were sent an information letter about the study and were asked to return the consent forms if they wanted to take part once they had read the information. Infants with DS were recruited through a variety of methods. Initially, the parents of infants who were taking part in language support groups at the University of Reading were sent an information letter and consent forms about the study, and were asked to get in touch, or return the consent forms if they wanted to take part. The parents of infants who were taking part in local language support groups were also approached by the experimenter and asked if they would like to take part in the study. The parents were given written and verbal information about the research study prior to testing and were informed that they were free to withdraw at any time without stating a reason.

\subsection{Participants}

In our original sample (see Table 1), thirty five TD infants (18 girls) were recruited into the study. All infants were being raised in a monolingual English speaking environment. 
192 Thirty children with DS (12 girls) were originally recruited into the study. Three infants were exposed to languages other than English, but English was the family's dominant language.

Demographic data were collected for the following variables: History of Hearing Infections (Yes/No); Other Languages (Yes/No); Maternal Employment Status (Employed Full Time, Employed Part Time, Self-Employed, Unemployed, Employed but on Maternity Leave); Highest Level of Maternal and Paternal Education (None, GCSE's, A-Level, NVQ or HND, Degree, Postgraduate Degree, Other).

Fischer's exact tests were used to check for group differences in the demographic variables at the start of the study (Time Point 1). There were no significant group differences for Sex $(p=.456)$, History of ear infections $(p=.705)$ Maternal education $(p=.510)$ and Paternal education $(p=.125)$. A significant difference between the groups was found for Other languages used at home $(p=.040)$, which was due to the fact that 4 children with DS were exposed to languages other than English but English was reported to be their dominant language. In all 4 cases children were born in the UK, were attending English speaking nurseries and the parents' common language was English. A significant difference was also found for Maternal employment ( $\mathrm{p}=.036)$, due to fewer of the mothers of children with DS working compared to mothers of typically developing children. The data for this original sample are presented in Table 1. 
Table 1: Mean and standard deviation of scores at each time point for the two groups (DS and TD) that completed each task

\begin{tabular}{|c|c|c|c|c|c|c|}
\hline & $\begin{array}{l}\text { TD1 } \\
(\mathrm{n}=35)\end{array}$ & $\begin{array}{l}\text { DS1 } \\
(n=30)\end{array}$ & $\begin{array}{l}\text { TD2 } \\
(\mathrm{n}=33)\end{array}$ & $\begin{array}{l}\text { DS2 } \\
(\mathrm{n}=28)\end{array}$ & $\begin{array}{l}\text { TD3 } \\
(n=32)\end{array}$ & $\begin{array}{l}\text { DS3 } \\
(\mathrm{n}=29)\end{array}$ \\
\hline & $\mathrm{CA}=10.4$ & $\mathrm{CA}=19.7$ & $\mathrm{CA}=16.8$ & $\mathrm{CA}=26.3$ & $\mathrm{CA}=23.1$ & $\mathrm{CA}=32.9$ \\
\hline & Range & Range & Range & Range & Range & Range \\
\hline & $9.3-11.16$ & $17.5-23.6$ & $16.3-17.9$ & $23.10-30.6$ & $22.6-24.1$ & $30.5-36.1$ \\
\hline \multirow{3}{*}{$\begin{array}{l}\text { NVMA } \\
\text { (MSEL) }\end{array}$} & $32.4 * *$ & $34.9 * *$ & $45.1 * * *$ & $41.1 * * *$ & $\mathrm{~N} / \mathrm{A}$ & 44.5 \\
\hline & $(s d=2.09)$ & $(\mathrm{sd}=4.11)$ & $(\mathrm{sd}=3.19)$ & $(\mathrm{sd}=5.20)$ & & $(\mathrm{sd}=5.18)$ \\
\hline & $\mathrm{n}=\mathbf{3 5}$ & $\mathbf{n}=\mathbf{3 0}$ & $\mathrm{n}=\mathbf{2 8}$ & $\mathrm{n}=\mathbf{2 8}$ & & $\mathrm{n}=25$ \\
\hline \multirow[t]{3}{*}{ AC (PLS-4) } & $17.5 * * *$ & $19.7 * * *$ & 23.4 & 24.2 & $34.5 * * *$ & $28.1 * * *$ \\
\hline & $(\mathrm{sd}=1.09)$ & $(\mathrm{sd}=3.20)$ & $(\mathrm{sd}=2.25)$ & $(\mathrm{sd}=2.89)$ & $(\mathrm{sd}=5.42)$ & $(\mathrm{sd}=4.31)$ \\
\hline & $\mathrm{n}=\mathbf{3 5}$ & $\mathbf{n}=\mathbf{3 0}$ & $\mathrm{n}=28$ & $\mathrm{n}=28$ & $\mathbf{n}=\mathbf{3 1}$ & $\mathrm{n}=\mathbf{2 9}$ \\
\hline \multirow[t]{3}{*}{ EC (PLS-4) } & 19.1 & 19.1 & $25.8 * * *$ & $23.8 * * *$ & $34.8 * * *$ & $26.3 * * *$ \\
\hline & $(\mathrm{sd}=2.06)$ & $(\mathrm{sd}=2.85)$ & $(\mathrm{sd}=1.89)$ & $(\mathrm{sd}=1.75)$ & $(\mathrm{sd}=5.24)$ & $(\mathrm{sd}=1.96)$ \\
\hline & $\mathrm{n}=35$ & $\mathrm{n}=30$ & $\mathrm{n}=\mathbf{2 8}$ & $\mathrm{n}=\mathbf{2 8}$ & $\mathbf{n}=\mathbf{3 1}$ & $\mathbf{n}=\mathbf{2 9}$ \\
\hline \multirow[t]{3}{*}{ RV (RCDI) } & $17.9 * * *$ & $66.2 * * *$ & 133 & 152 & $344 * * *$ & $220 * * *$ \\
\hline & $(\mathrm{sd}=20.9)$ & $(\mathrm{sd}=51.6)$ & $(\mathrm{sd}=87.8)$ & $(\mathrm{sd}=80.8)$ & $(\mathrm{sd}=112)$ & $(\mathrm{sd}=104)$ \\
\hline & $\mathrm{n}=\mathbf{3 4}$ & $\mathbf{n}=\mathbf{2 9}$ & $\mathrm{n}=32$ & $\mathrm{n}=25$ & $\mathrm{n}=\mathbf{2 5}$ & $\mathbf{n}=\mathbf{2 7}$ \\
\hline \multirow[t]{3}{*}{ EV (RCDI) } & $1.03 *$ & $3.38 *$ & 33.3 & 17.8 & $223 * * *$ & $46 * * *$ \\
\hline & $(\mathrm{sd}=1.75)$ & $(\mathrm{sd}=4.40)$ & $(\mathrm{sd}=39.4)$ & $(\mathrm{sd}=22.2)$ & $(\mathrm{sd}=138)$ & $(\mathrm{sd}=56.4)$ \\
\hline & $\mathrm{n}=\mathbf{3 4}$ & $\mathrm{n}=\mathbf{2 9}$ & $\mathrm{n}=32$ & $\mathrm{n}=26$ & $\mathrm{n}=\mathbf{2 5}$ & $\mathbf{n}=\mathbf{2 7}$ \\
\hline
\end{tabular}

CA - chronological age in months and days; TD1 - typically developing children, time point 1; TD2- typically developing children, time point 2; TD3 - typically developing infants, time point 3; DS1- infants with Down syndrome, time point 1; DS2- infants with Down syndrome, time point 2; DS3-infants with Down syndrome, time point 3; NVMA - non-verbal mental ability- combined raw scores on the Visual Reception and Fine Motor scales of the Mullen's Scale of Early Learning (MSEL); AC - auditory comprehension; EC- expressive communication; PLS-4 -Pre-school Language Scales-4; RV - receptive vocabulary; EV-expressive vocabulary; RCDI-Reading Child Development Inventory; $*=p<.05 ; * *=p<.01 ; * * *=p \leq .001$. 
ways: a) at three time points during a 12 month period, when the infants with DS were 18-20 infants, and 12 months for the infants with DS. See Table 2 below for a visual illustration of the analysis schedule.

Table 2: Study design

\begin{tabular}{|c|c|c|c|}
\hline \multicolumn{4}{|c|}{ COMPARISON 1 (at fixed time intervals) } \\
\hline & Time Point 1 & Time Point 2 & Time Point 3 \\
\hline & CA & $\mathrm{CA}$ & CA \\
\hline DS & Mean: $19 ; 7$ & Mean: $26 ; 1$ & Mean: $32 ; 8$ \\
\hline \multirow[t]{2}{*}{$n=18$} & range: $17 ; 5-23 ; 6$ & range: $24 ; 0-30 ; 6$ & range: $30 ; 5-36 ; 1$ \\
\hline & $\mathrm{CA}$ & $\mathrm{CA}$ & $\mathrm{CA}$ \\
\hline TD & Mean:10;10 & Mean:16;22 & Mean: $23 ; 0$ \\
\hline \multirow[t]{3}{*}{$n=26$} & range: $9 ; 4-11 ; 2$ & range: $16 ; 3-17 ; 9$ & range $22 ; 6-24 ; 2$ \\
\hline & \multicolumn{3}{|c|}{ COMPARISON 2 (when groups made equal gains in NVMA scores) } \\
\hline & Time Point 1 & & Time Point 2 \\
\hline DS & $\mathrm{CA}$ & & $\mathrm{CA}$ \\
\hline \multirow[t]{5}{*}{$\mathrm{n}=18$} & Mean:19;7 & & Mean: $32 ; 8$ \\
\hline & range: $17 ; 5-23 ; 6$ & & range: $30 ; 5-36 ; 1$ \\
\hline & *NVMA scores & & *NVMA scores \\
\hline & mean 32.94 & & mean 43.55 \\
\hline & range: $25-37$ & & range $34-51$ \\
\hline TD & $\mathrm{CA}$ & & CA \\
\hline \multirow[t]{5}{*}{$n=26$} & Mean:10;10 & & Mean: 16;22 \\
\hline & range: $9 ; 4-11 ; 2$ & & range: $16 ; 3-17 ; 9$ \\
\hline & *NVMA scores & & *NVMA scores \\
\hline & mean 32.46 & & mean 45.34 \\
\hline & range $30-37$ & & range $38-55$ \\
\hline
\end{tabular}


237 At Time Point 1, the DS group had significantly higher non-verbal mental ability as measured 238 by the Mullen Scale of Early Learning (Mullen, 1995) than the TD group, $[\mathrm{t}(1,41.540)=$ $2392.975, \mathrm{p}=0.05)$. To match the groups on non-verbal mental ability at the first point of 240 measurement, we first excluded cases with missing data for either non-verbal mental ability 241 or general language measures (Pre-School Language Scale data, see below) at Time Points 1, 2 or 3. This left 26 typically-developing infants, and 23 infants with DS who had completed non-verbal mental ability and language measures at all three time points. An independent samples t-test revealed that these groups were not significantly different in terms of NVMA at Time Point 1: $t(30.8)=-1.98, p=.057$. However, Mervis \& Robinson (2003) recommend that groups cannot be assumed to be matched on a control variable unless a $p$ value of at least 0.50 is found in the test of group differences. In addition to this, according to Piaggio, Elbourne, Altman, Pocock and Evans, (2006), groups are matched if there is an adequately small effect size "which might be defined as the smallest value at which a difference in groups would be clinically meaningful" (Piaggio et al., 2006 in Kover \& Atwood, p.6). Rubin (2001) proposed that the standardized mean difference be close to zero (less than half a standard deviation apart; $\mathrm{d} \leq .5$ ). We therefore further removed the highest scoring participants with DS until the groups were matched by this criterion. Thus the final sample has 26 typically-developing infants and 18 infants with DS matched for non-verbal mental ability: $t(24.7)=-.567, p=.576$, Cohen's $\mathrm{d}=0.15$ (see Table 3 for matched group comparisons on all measures). 
Table 3: Mean and standard deviation of scores at each time point for the two matched groups (DS and TD) that completed each task when matched for NVMA at Time Point 1

\begin{tabular}{|c|c|c|c|c|c|c|}
\hline & $\begin{array}{l}\text { TD1 } \\
(n=26) \\
C A=10.1\end{array}$ & $\begin{array}{l}\text { DS1 } \\
(n=18) \\
C A=19.2\end{array}$ & $\begin{array}{l}\text { TD2 } \\
(n=26) \\
C A=16.2\end{array}$ & $\begin{array}{l}\text { DS2 } \\
(n=18) \\
C A=26.1\end{array}$ & $\begin{array}{l}\text { TD3 } \\
(n=26) \\
C A=23\end{array}$ & $\begin{array}{l}\text { DS3 } \\
(\mathrm{n}=18) \\
\mathrm{CA}=32.8\end{array}$ \\
\hline $\begin{array}{l}\text { NVMA } \\
\text { (MSEL) }\end{array}$ & $\begin{array}{l}32.5 \\
(\mathrm{sd}=1.86)\end{array}$ & $\begin{array}{l}32.9 \\
(\mathrm{sd}=3.26)\end{array}$ & $\begin{array}{l}45.3 * * * \\
(\mathrm{sd}=3.20)\end{array}$ & $\begin{array}{l}38.9 * * * \\
(\mathrm{sd}=3.08)\end{array}$ & $\mathrm{N} / \mathrm{A}$ & $\begin{array}{l}43.6 \\
(\mathrm{sd}=4.98)\end{array}$ \\
\hline AC (PLS-4) & $\begin{array}{l}17.4 * * * \\
(\mathrm{sd}=1.14)\end{array}$ & $\begin{array}{l}19.2 * * * \\
(\mathrm{sd}=2.05)\end{array}$ & $\begin{array}{l}23.5 \\
(\mathrm{sd}=2.32)\end{array}$ & $\begin{array}{l}23.6 \\
(\mathrm{sd}=2.33)\end{array}$ & $\begin{array}{l}34.2 * * * \\
(\mathrm{sd}=5.48)\end{array}$ & $\begin{array}{l}27.0 * * * \\
(\mathrm{sd}=3.40)\end{array}$ \\
\hline EC (PLS-4) & $\begin{array}{l}18.8 \\
(\mathrm{sd}=1.89)\end{array}$ & $\begin{array}{l}18.3 \\
(\mathrm{sd}=2.22)\end{array}$ & $\begin{array}{l}25.6 * * \\
(\mathrm{sd}=1.86)\end{array}$ & $\begin{array}{l}23.8 * * \\
(\mathrm{sd}=1.73)\end{array}$ & $\begin{array}{l}34.9 * * * \\
(\mathrm{sd}=5.21)\end{array}$ & $\begin{array}{l}25.6 * * * \\
(\mathrm{sd}=1.58)\end{array}$ \\
\hline RV (RCDI) & $\begin{array}{l}18.3 * * \\
(s d=20.7)\end{array}$ & $\begin{array}{l}41.5 * * \\
(\mathrm{sd}=31.8)\end{array}$ & $\begin{array}{l}137 \\
(\mathrm{sd}=91.2)\end{array}$ & $\begin{array}{l}124 \\
(\mathrm{sd}=66.8)\end{array}$ & $\begin{array}{l}347 * * * \\
(\mathrm{sd}=107)\end{array}$ & $\begin{array}{l}190 * * * \\
(\mathrm{sd}=94.8)\end{array}$ \\
\hline $\mathrm{EV}$ (RCDI) & $\begin{array}{l}0.77 \\
(\mathrm{sd}=1.14)\end{array}$ & $\begin{array}{l}2.83 \\
(\mathrm{sd}=4.68)\end{array}$ & $\begin{array}{l}32.9 \\
(\mathrm{sd}=42.1)\end{array}$ & $\begin{array}{l}18.1 \\
(\mathrm{sd}=24.1)\end{array}$ & $\begin{array}{l}228 * * * \\
(\mathrm{sd}=139)\end{array}$ & $\begin{array}{l}32.1 * * * \\
(\mathrm{sd}=36.3)\end{array}$ \\
\hline
\end{tabular}

CA - chronological age in months and days; TD1 - typically developing children, time point 1; TD2- typically developing children, time point 2; TD3 - typically developing infants, time point 3; DS1- infants with Down syndrome, time point 1; DS2- infants with Down syndrome, time point 2; DS3-infants with Down syndrome, time point 3; NVMA - non-verbal mental ability- combined raw scores on the Visual Reception and Fine Motor scales of the Mullen's Scale of Early Learning (MSEL); AC - auditory comprehension; EC- expressive communication; PLS-4 -Pre-school Language Scales-4; RV - receptive vocabulary; EV-expressive vocabulary; RCDI-Reading Child Development Inventory; $*=p<.05 ; * *=p<.01 ; * * *=p \leq .001$. months and 10 days (range 9 months 4 days-11 months 2 days) at Time Point 1; 16 months 
277 (range 17 months 5 days-23 months 6 days) at Time Point 1; 26 months and 10 days (range

24 months- 30 months 6 days) at Time Point 2; and 32 months and 8 days (range 30 months 5 days-36 months 1 day) at Time Point 3. Of these, 2 infants were exposed to languages other than English, but English was the family's dominant language.

Fischer's exact tests were used to check for group differences in the demographic variables. There were no significant group differences for Sex $(p=.547)$, History of ear

Paternal employment ( $p=.162)$. A significant difference was found for Maternal employment $(\mathrm{p}=.024)$, due to the fact that fewer of the mothers of children with DS were working compared to mothers of typically developing children. However, because there were no differences in maternal education, maternal employment status was not used as an exclusion criterion. receptive and expressive general language, expressive and receptive vocabulary and nonverbal mental ability. The measures are described below. standardised measure of cognitive functioning for infants aged 0-68 months. Two of the five scales were administered: the Visual Reception scale and the Fine Motor scale. The Visual Reception Scale tests the infant's visual discrimination and visual memory, and requires the skills of visual organisation, visual sequencing, and visual spatial awareness, including 
concepts of size, shape, and position. The Fine Motor Scale provides a measure of visualmotor ability. The items on this subscale require visually-directed motoric planning, and primarily assess unilateral and bilateral manipulation. Non-Verbal Mental Ability scores were derived by combining the raw scores of the Visual Reception and Fine Motor scales. T-scores were not used, as most infants with DS obtained the lowest possible value (20), masking the variability in their raw scores. Converting to T-scores would also make group comparisons meaningless, due to the differences in the groups' chronological ages.

\section{Preschool Language Scales-4 (PLS-4)}

The PLS is a standardised assessment composed of two subscales: Auditory

Comprehension and Expressive Communication. The Auditory Comprehension subscale evaluates understanding of language and the Expressive Communication subscale was used to determine how well children communicated with others, vocally and socially. Please note that these two measures of general receptive and expressive language do not exclusively focus on grammar. Receptive and expressive language scores were derived from the raw scores on the Auditory Comprehension and the Expressive Communication subscales respectively. Standardised scores were not used, as standardised scores for the infants with DS were often the lowest possible value (55), masking the variability in infants' raw scores.

Converting raw scores to standardised scores would have made group comparisons of language abilities meaningless, due to the differences in the groups' chronological ages. Use of raw scores is common in the literature on atypical populations (for example: Klein \& Mervis, 1999; Mason-Apps et al., 2018; Seager et al., 2018, van Herwegen, Tim, Smith \& Dimitriou, 2015).

\section{Reading Communicative Development Inventory (Reading CDI)}

Receptive and Expressive Vocabulary scores were measured using the Reading Communicative Development Inventory (CDI), an adaptation of the Oxford CDI (Hamilton, 
Plunkett, \& Schafer, 2000). This is a parental report measure, comprising a checklist of words that a child might know, in 20 semantic categories, and additional sections to indicate use of word endings, word forms, and sentences. Parents were sent the checklist to complete at home in the week prior to their visit. Parents were asked to indicate which words their child understood (but did not say), which words the child said, and which words their child both understood and said. Parents of infants with DS were also asked to indicate which words the child both understood and produced signs for. Receptive Vocabulary scores were derived from the number of words parents indicated that the child understood or understood and said. Expressive Vocabulary scores were derived from the number of words that the parents indicated that the child understood and said. Signs were excluded from the calculation of scores.

\subsection{Results}

To address the first aim of the study, first we present between group comparisons at each time point (TP1, TP2 and TP3), for the TD children and participants with DS matched on NVMA at TP1. Then, in order to address the second aim of the study, we compare the language development of the two groups over a period when they have made similar gains in non-verbal mental ability (which is at two time points only, i.e. Time Point 2 for the TD group and Time Point 3 for the DS group)

\subsection{Between group comparisons at each time point of testing (to address aim 1)}

To address the first aim of the study, we first present comparisons between the TD children and participants with DS (matched on NVMA at TP1) at each time point (TP1, TP2 and TP3). A 2 × 3 mixed design ANOVA was run in each analysis, with Group as betweensubjects variable, and Time as a within-subjects variable. Table 3 above shows the raw scores for each group on all the measures collected at each time point. Significant group differences are marked with an asterisk. 

each Time Point, $F(1.30,51.8)=231.366, p<.001\left(\eta^{2}=.853\right)$. There was a main effect of Group, $F(1,40)=5.631, p=.023\left(\eta^{2}=.123\right)$, and a significant Group $\mathrm{x}$ Time interaction, $F(1.30,51.8)=35.268, p<.001\left(\eta^{2}=.469\right)$. significant gains in $\mathrm{AC}$ scores at each time point (all $p s<.001)$. The DS group had significantly higher $\mathrm{AC}$ scores than the TD group at $\mathrm{TP} 1, F(1,40)=12.566, p=.001$ compared to the DS group at Time Point 3, $F(1,40)=24.130, p<.001\left(\eta^{2}=.376\right)$.

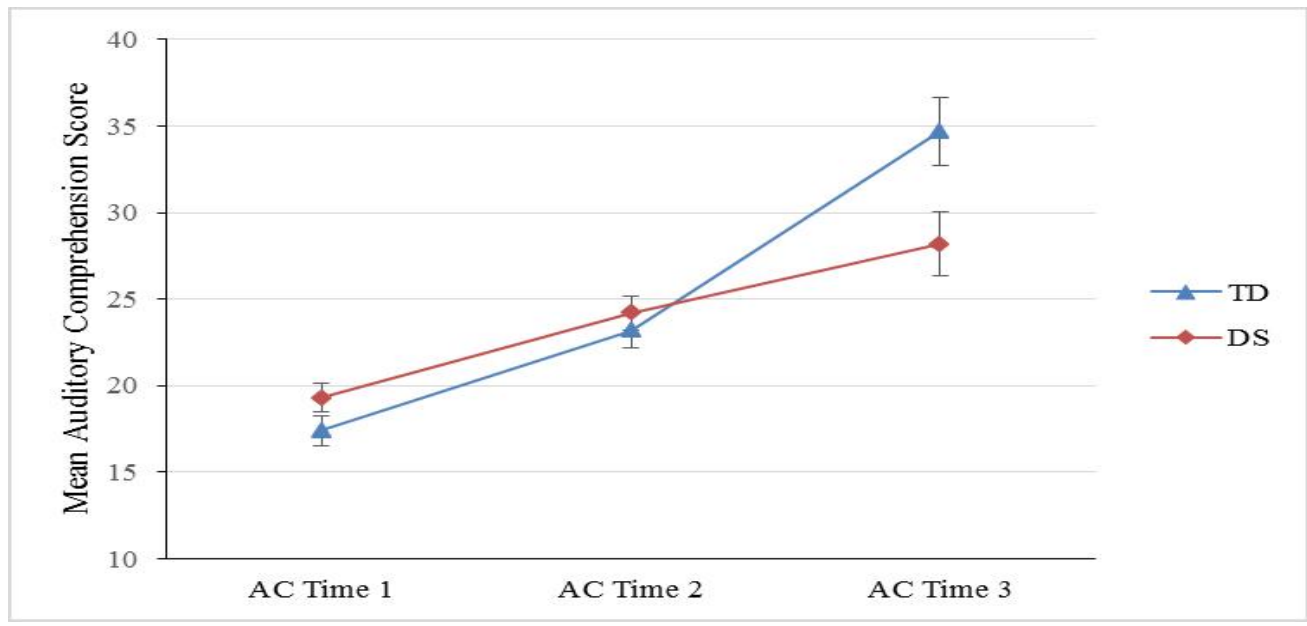

Figure 1. Mean Auditory Comprehension scores for the TD and DS groups at Time Point 1, Time Point 2, and Time Point 3 

groups at TP1, TP2 and TP3. The ANOVA found a main effect of Time, $F(1.41,56.4)=$ 310.477, $p<.001\left(\eta^{2}=.886\right)$, with EC scores increasing at each Time Point. There was a significant main effect of Group, $F(1,40)=30.814, p<.001\left(\eta^{2}=.435\right)$, and a significant Group $x$ Time interaction, $F(1.41,56.4)=50.843, p<.001\left(\eta^{2}=.560\right)$.

Simple main effects analysis revealed that both the TD and DS group made significant gains in EC scores at each time point (for the TD group, all $p s<.001$; for the DS group TP1 andTP2, $p<.001$, and for TP2 andTP3, $p=.019)$. The analysis also showed that there were no significant differences between the TD and DS group at Time Point $1, F(1,40)$ $=0.991, p=.325\left(\eta^{2}=.024\right)$. However, the TD group had significantly higher EC scores than the DS groups at TP 2, $F(1,40)=9.308, p=.004\left(\eta^{2}=.189\right)$, and Time Point $3, F(1,40)=$ $53.485, p<.001\left(\eta^{2}=.572\right)$.

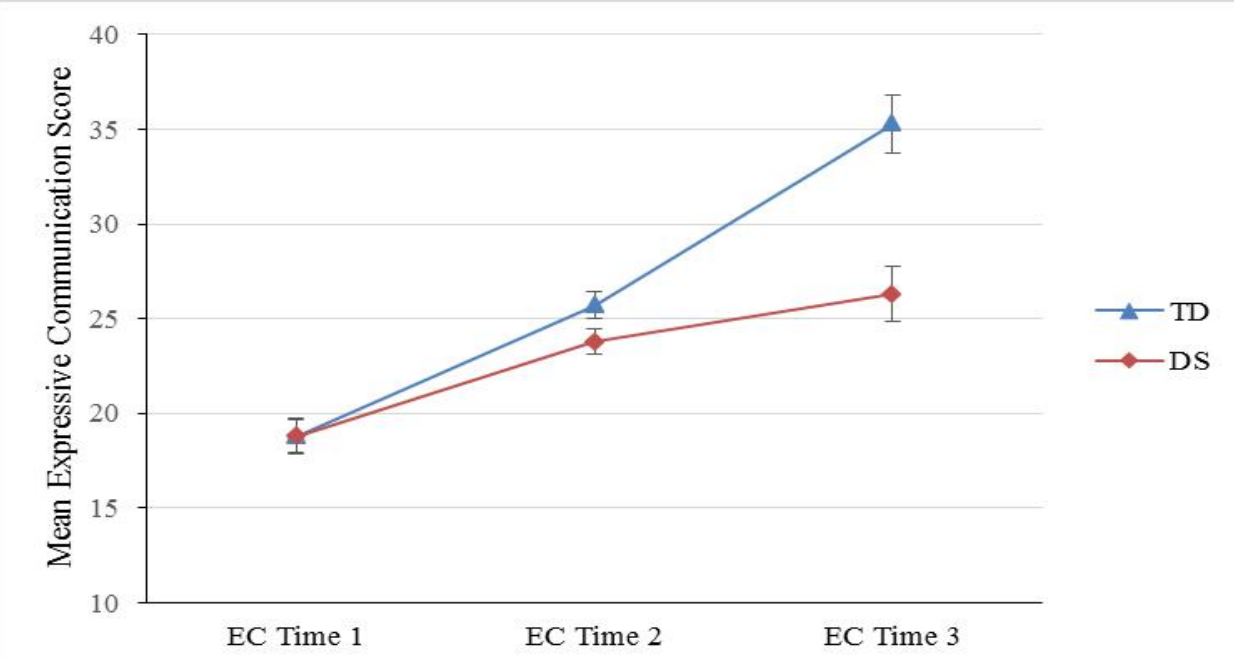

Figure 2. Mean Expressive Communication scores for the TD and DS groups at Time Point 1, Time Point 2, and Time Point 3

\subsubsection{Receptive Vocabulary}

Figure 3 shows the mean Receptive Vocabulary (RV) scores for the typicallydeveloping group (TD) and the group of infants with Down syndrome (DS) at TP1, TP2 and TP3. Data is only presented for those participants for whom RV data was available at all 
three time points (for the typically-developing group, $\mathrm{N}=21$; for the group of infants with DS, $\mathrm{N}=17$ ). The ANOVA found a main effect of Time, with RV scores increasing at each Time Point, $F(1.45,52.2)=209.392, p<.001\left(\eta^{2}=.853\right)$. There was a significant main effect of Group, $F(1,36)=4.593, p=.039\left(\eta^{2}=.113\right)$, and a significant Group x Time interaction, $F(1.45,52.2)=33.350, p<.001\left(\eta^{2}=.481\right)$.

Simple main effects analysis revealed that both the TD and DS group made 392 significant gains in RV scores at each time point (all ps $<.001$ ). The analysis also showed significantly higher RV scores for the DS than the TD group at Time Point $1, F(1,36)=$ $10.497, p=.003\left(\eta^{2}=.226\right)$, no significant differences between the DS and TD group at Time Point 2, $F(1,36)=0.005, p=.945\left(\eta^{2}<.001\right)$, significantly higher RV scores for the TD group compared to the DS group at Time Point 3, $F(1,36)=21.024, p<.001\left(\eta^{2}=.369\right)$.

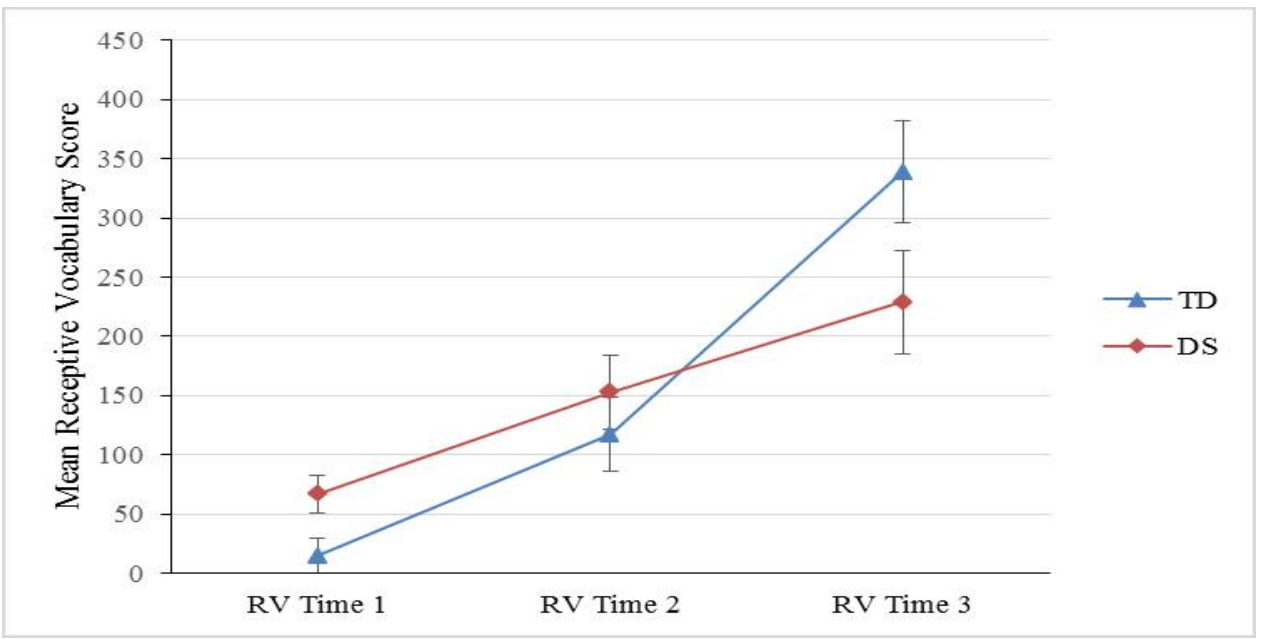

Figure 3. Mean Receptive Vocabulary scores for the TD and DS groups at Time Point 1, Time Point 2, and Time Point 3

\subsubsection{Expressive Vocabulary}

Figure 4 shows the mean Expressive Vocabulary (EV) scores for the typically402 developing group (TD) and the group of infants with Down syndrome (DS) at TP1, TP2 and TP3. Data is only presented for those participants for whom Expressive Vocabulary data was available at all three time points (for the TD group, $\mathrm{N}=21$, for the $\mathrm{DS}$ group, $\mathrm{N}=17$ ). The 
405

406

407

408

409

410

411

412

413

414

415

416

417

418

419

420

421

422

423

424

ANOVA found a main effect of Time, with EV scores increasing at each Time Point, $F(1.08,38.9)=53.681, p<.001\left(\eta^{2}=.599\right)$. There was a significant main effect of Group, $F(1,40)=23.239, p<.001 \quad\left(\eta^{2}=.392\right)$, and a significant Group $x$ Time interaction, $F(1.08,38.9)=34.123, p<.001\left(\eta^{2}=.487\right)$.

Simple main effects analysis revealed that the TD group made significant gains in EV scores at each time point (all ps<.001). For the DS group, the gain in EV scores between TP1 and TP2 was significant $(\mathrm{p}=.030)$, but the gain between TP2 and TP3 was not $(p=$ $.481)$. There were no significant differences between the TD and DS groups at $\mathrm{TP} 1, F(1,36)=$ $3.609, p=.066\left(\eta^{2}=.091\right)$, or TP2, $F(1,36)=.612, p=.439\left(\eta^{2}=.017\right)$, but the TD group had significantly higher EV scores than the DS group at TP3, $F(1,36)=31.372, p<.001$ $\left(\eta^{2}=.466\right)$.

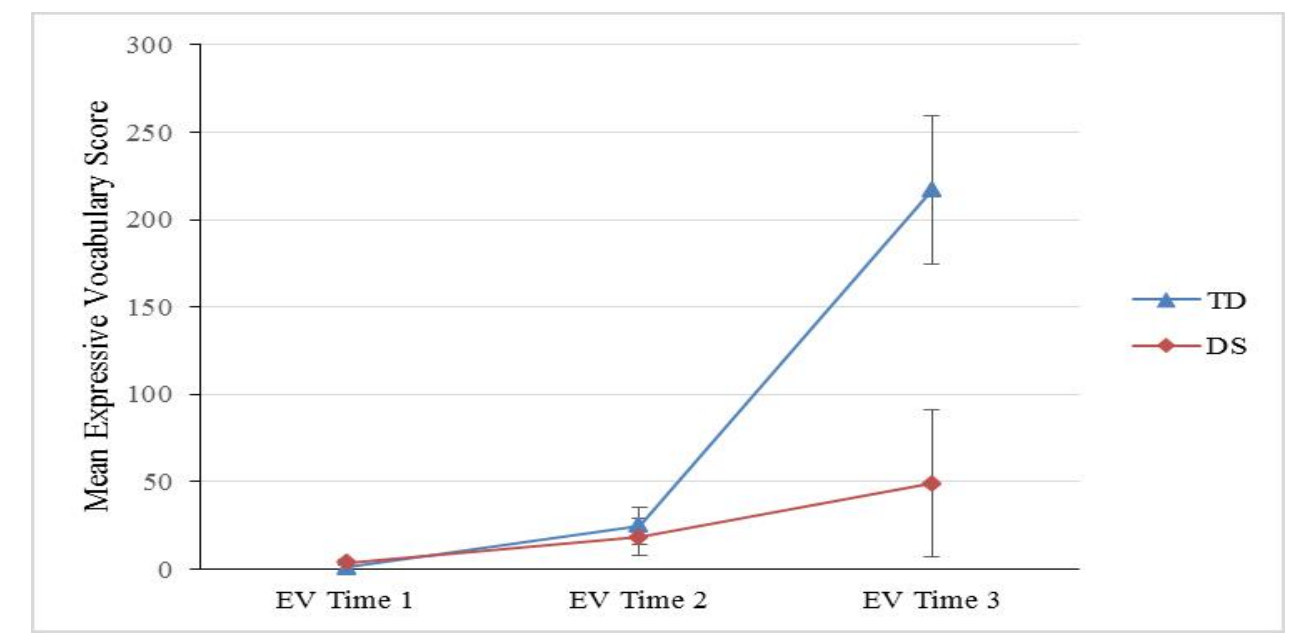

Figure 4. Mean Expressive Vocabulary scores for the TD and DS groups at Time Point 1, Time Point 2, and Time Point 3

\subsection{Language development when the two groups are matched on growth in Non-}

\section{Verbal Mental Ability (to address aim 2 of the study)}

To address the second aim of the study, we compared the language development of the two groups over a period when they had made similar gains in non-verbal mental ability (i.e. from TP 1 to TP 2 for the TD group and from TP 1 to TP 3 for the DS group). This was a period of 
42512 months for the DS group and 6 months for the TD group. At the final time points included, 426 the two groups did not differ in NVMA, $t(1,42)=1.45, \mathrm{p}=.154$, Cohen's $\mathrm{d}=0.42$. For each 427 analysis, we ran a mixed-design ANOVA, with Group (TD, DS1) as a between-subjects 428 variable, and Time (TP1 and either TP2 or TP3 depending on group) as a within-subjects 429 variable.

\subsubsection{Auditory Comprehension}

431

Figure 5 shows the mean AC scores for the TD group (at Time Point 1 and 2) and the DS group (at Time Point 1 and 3). There was main effect of Time, with AC scores increasing between the two time points, $F(1,42)=245.734, p<.001\left(\eta^{2}=.854\right)$. The ANOVA found a significant main effect of Group, $F(1,42)=24.173, p<.001\left(\eta^{2}=.365\right)$, but the Group $\mathrm{x}$ Time interaction was not significant $F(1,42)=3.703, p=.061\left(\eta^{2}=.081\right)$. Infants with DS had significantly better auditory comprehension than matched TD peers.

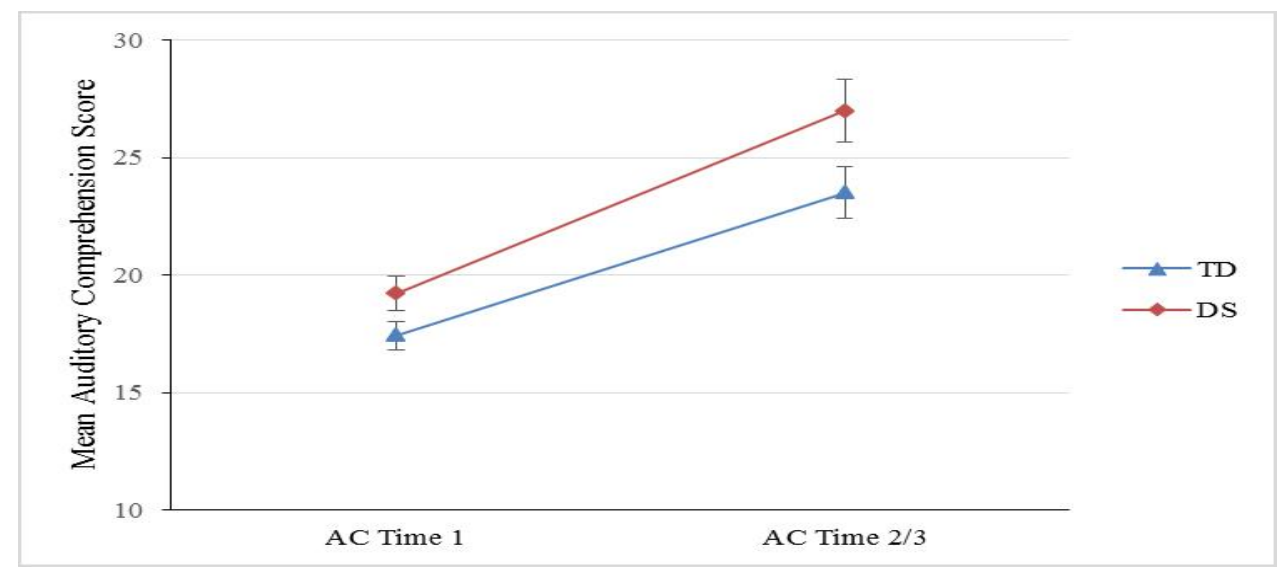

Figure 5. Mean Auditory Comprehension scores for the typically-developing group at Time Point 1 and Time Point 2, and for the group of infants with Down syndrome at Time Point 1 and Time Point 3, when groups were matched for NVMA

\subsubsection{Expressive Communication}


445 Communication scores increasing between the two time points (TP1 and TP2 for the TD 446 group and TP1 and TP3 for the DS group), $F(1,42)=567.289, p<.001\left(\eta^{2}=.931\right)$ for both 447 groups. There was no main effect of Group, $F(1,42)=0.328, p=.570\left(\eta^{2}=.008\right)$, and no 448 significant Group x Time interaction, $F(1,42)=0.908, p=.346\left(\eta^{2}=.021\right)$. The Expressive 449 Communication skills of children with DS were in line with those of their NVMA growth450 matched peers.

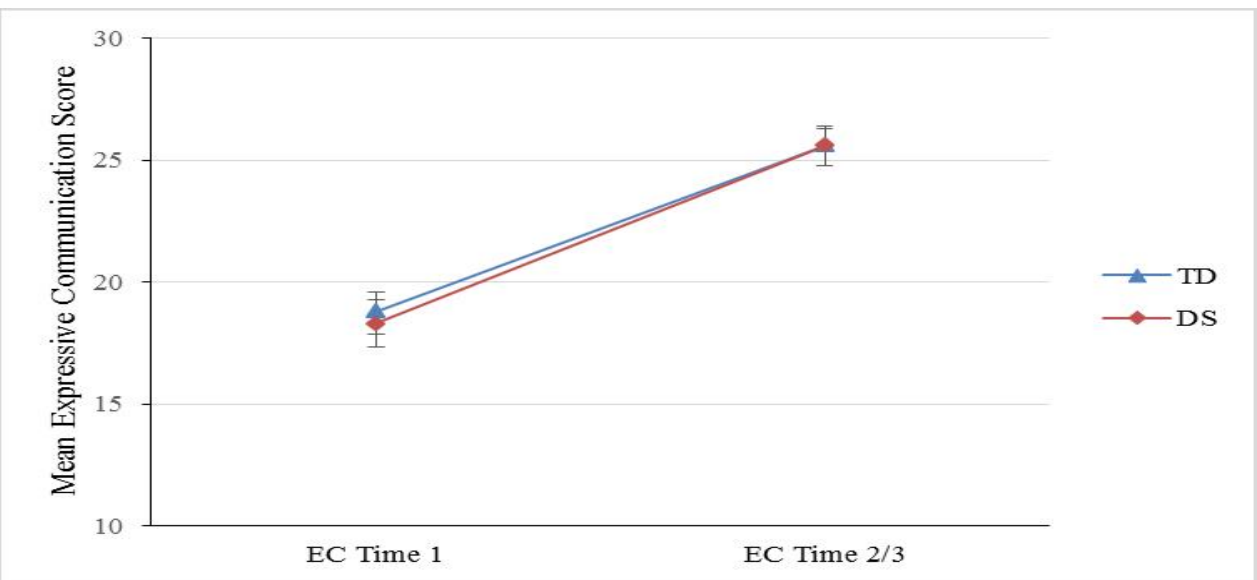

Figure 6. Mean Expressive Communication scores for the typically-developing group at Time Point 1 and Time Point 2, and for the group of infants with Down syndrome at Time Point 1 and Time Point 3, when groups were matched for NVMA

\subsubsection{Receptive Vocabulary}

Figure 7 shows the mean RV scores for the TD group (at Time Point 1 and 2) and for 457 the DS group (at Time Point 1 and 3). There was a main effect of Time, with RV scores 458 increasing between the two time points, $F(1,42)=11.940, p<.001\left(\eta^{2}=.739\right)$. The ANOVA 459 found a main effect of Group, $F(1,42)=5.033, p=.030\left(\eta^{2}=.107\right)$, but no significant Group $460 \mathrm{x}$ Time interaction, $F(1,42)=1.441, p=.237\left(\eta^{2}=.033\right)$. Infants with DS had significantly 461 larger receptive vocabularies than their matched TD counterparts. 


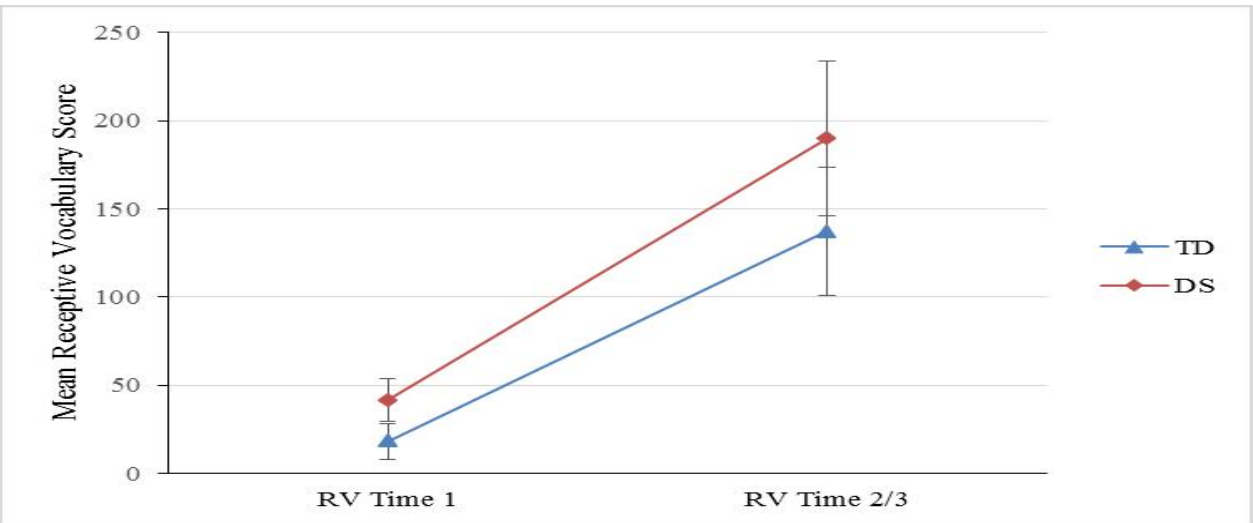

Figure7. Mean Receptive Vocabulary scores for the typically-developing group at Time Point 1 and Time Point 2, and for the group of infants with Down syndrome at Time Point 1 and Time Point 3, when groups were matched for NVMA

\subsubsection{Expressive Vocabulary}

Figure 8 shows the mean EV scores for the TD group (at TP1 and TP2) and for the DS group (at TP1 and TP3). There was a main effect of Time, with EV scores increasing significantly between the two time points, $F(1,42)=26.000, p<.001\left(\eta^{2}=.382\right)$. The ANOVA found no main effect of Group, $F(1,42)=0.009, p=.924\left(\eta^{2}<.001\right)$, and no significant Group $x$ Time interaction, $F(1,42)=0.059, p=.809\left(\eta^{2}=.001\right)$.

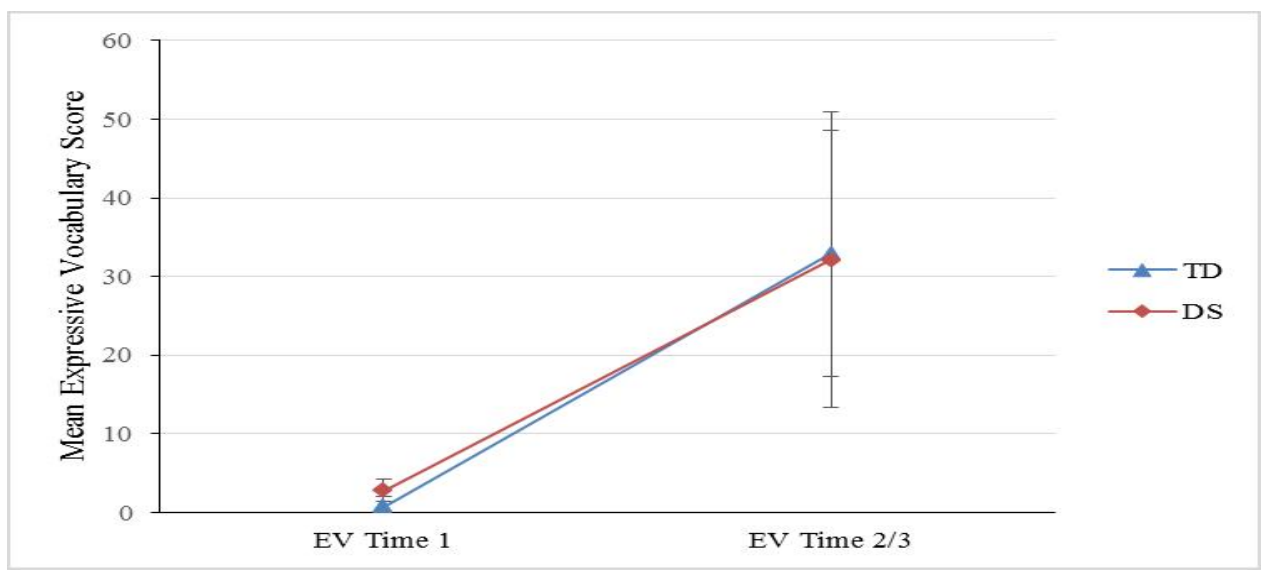

Figure 8. Mean Expressive Vocabulary scores for the typically-developing group at Time Point 1 and Time Point 2, and for the group of infants with Down syndrome at Time Point 1 and Time Point 3, when groups were matched for NVMA 


\subsection{Discussion}

The purpose of this paper was to investigate the course of language development in a group of infants with DS compared to a group of TD infants. Specifically, we wanted to find out how language develops over the course of one calendar year after an initial time point at which groups did not differ in terms of non-verbal abilities. The second aim was to compare the trajectories of language development shown by the two groups across a period in which the groups made equal progress in their non-verbal mental ability (6 months for the TD infants; 12 months for the infants with DS).

The results of the whole groups' analyses, which was the first aim of the study, showed that, although the DS group were ahead of the TD group on auditory comprehension and receptive vocabulary at Time Point 1 , by Time Point 2 (a period of 6 months), the TD group has already caught up with the DS group on auditory comprehension and receptive vocabulary, and significantly outperformed the DS group on expressive communication. By Time Point 3, which was a period of 12 months, the TD group significantly outperformed the DS group on all language and vocabulary measures. These finding are in line other research studies which have shown that language in children with DS develops more slowly than in typically developing children (Abbeduto, Warren \& Conners, 2007; Levy \& Eilam, 2013). Inspection of the trajectories in our study seems to suggest that children with DS have more delays in expressive than in receptive language. For example, while TD children are reported to produce an average of 228 words by Time Point 3 , children with DS are reported to produce on average of 32 words. With regard to receptive vocabulary, on the other hand, children with DS are reported to understand on average 190 words compared to 347 for the TD children, which is a smaller discrepancy between the TD and DS groups compared to expressive vocabulary. Such results suggest potential strengths with regard to receptive 
vocabulary and are in line with what has already been reported about a possible receptive vocabulary advantage (Abbeduto et al., 2007; Caselli et al., 1998; Miller et al., 1999).

The second aim of the study was to compare the trajectories of language development between the two groups across a period in which the groups had made equal progress in their non-verbal mental ability. Our findings show that, once the language abilities were compared when both the TD and DS groups had made equal gains in terms of non-verbal mental ability development, both expressive communication and expressive vocabulary showed the same rate and level of development for the infants with DS as for the TD infants. Importantly, receptive vocabulary and auditory comprehension were significantly higher for the DS group compared to the TD group. Furthermore, for all four language measures, the trajectory of development in the DS group was very close to that of the TD group. There were no interactions between Time and Group in any analysis, showing that early expressive language in infants with DS seems to be developing entirely in line with their non-verbal mental abilities. This pattern was consistent for the two expressive (both vocabulary and general expressive communication) and two receptive assessments (vocabulary and general auditory comprehension). The data show that when non-verbal mental ability is taken into account, expressive communication and expressive vocabulary in the children with DS seem to be comparable to the TD group. On the other hand, both auditory comprehension and receptive vocabulary scores in the DS group were above those of the TD group, suggesting that our group of infants with DS may display a receptive language advantage at both time points relative to their non-verbal ability. This finding is in line with the findings of Galeote, Sebastian, Cheka, Rey and Soto (2011) for Spanish speaking children with Down syndrome who also reported that expressive vocabulary did not lag behind non-verbal mental ability, and that the receptive vocabulary of infants with DS was larger than that of mental age matched controls. Our findings, however, do not fully support those of Zampini and 
D’Odorico (2013) who used the Italian version of the MacArthur-Bates Communicative

529

Development Inventories and found significant differences in productive vocabulary size between children with DS and typically developing developmental age matched controls. However, it should be pointed out that the children with DS in the Zampini and D'Odorico's study were older at the first point of measurement (they had a developmental age of 18 months at the first time point whereas the infants with DS in our study had a non-verbal mental age of 9-10 months at the first time point). Thus our study captures the earliest stages of language acquisition in DS and shows that, at the point when expressive vocabulary and expressive communication emerge, children with DS are likely to be no different from typically developing children of a similar non-verbal mental ability.

\subsection{Do expressive and receptive language in infants with Down syndrome} develop atypically compared to neurotypical infants?

The data from our study suggest that when infants with Down syndrome are in the pre-linguistic and early stages of linguistic development, i.e. between 18 and 32 months of age, they seems to be delayed only to the extent expected given their non-verbal mental ability. This suggests that the language of infants with DS may not yet be developing atypically compared to neuro-typical infants. Importantly, our group of infants with Down syndrome: 1) did not seem to show any expressive language deficits, relative to their nonverbal mental ability, when compared to the typically-developing group at Time Point 1; and 2) showed a relative strength in receptive vocabulary and auditory comprehension compared to TD infants of a similar non-verbal mental ability.

It is generally accepted that a discrepancy between receptive and expressive language skills is characteristic of the typical adult phenotype for individuals with Down syndrome. Hence, one could argue that the widely-reported relative strengths in receptive language abilities (including both general understanding of language and receptive vocabulary) are 
present in Down syndrome from early on in development, mirroring the adult phenotype.

554 This would be too simplistic an explanation.

555

556

557

558

559

560

561

562

563

564

565

566

567

568

569

570

571

572

573

574

575

576

577

The picture is more complex because the infants with Down syndrome in our study did not show any deficits in expressive language skills relative to non-verbal mental ability when compared to the typically-developing infants at Time Point 1 . At Time Point 3, their expressive language skills (including expressive vocabulary and expressive communication) were in line with their non-verbal mental abilities. On the basis of the adult Down syndrome phenotype, one would expect expressive language (expressive vocabulary and/or general expressive communication) to be lagging behind non-verbal mental ability (Abbeduto et al., 2007; Chapman, Seung, Schwartz, \& Kay-Raining Bird, 1998). This was not the case with our findings. The reason for this may be that our control group were very young at the first time point (between 9-10 months of age), when infants are still predominantly babbling and do not produce language as such. Thus, when compared to infants with Down syndrome aged 18-22 months who were also predominantly still in the babbling stage, no differences in expressive language were evident between children with DS and neurotypical children. Importantly, however, the expressive language skills in the Down syndrome group appeared to be following the same developmental trajectory as the typically-developing group. It is likely that we did not find any differences between the groups because neither group had started using grammar yet (in terms of combining two words/morphemes). In the Levy and Eilam (2013) study, it was the onset of combinatorial language (i.e. the onset of combining two morphemes together) which was very delayed for some young children with DS.

The fact that an early expressive language deficit was not apparent at this early stage of development suggests that the later (and finally adult) DS language phenotype may emerge as a function of development. Deficits in expressive language skills relative to receptive language and general non-verbal mental ability in individuals with DS become more obvious 
once two-word combinations increase (Chapman, Hesketh \& Kistler, 2002). A limitation of the current study is the fact that the groups were only followed for one year after the initial time point. At the final time point, the TD group had a mean age of 23 months and the group of infants with DS had a mean age of 32 months. Because the infants were quite young at the final time point, both groups were still in the very early stages of language acquisition, with some participants having not even advanced to combining two words. Since it is expressive language and syntax development that are highlighted as particular areas of difficulty for individuals with DS, especially in later childhood and adulthood, it would be informative if the infants from this study were followed up at a later stage, when relative difficulties with grammar may have become more apparent.

Despite the limitations of studying infants in the earliest stages of language development, by comparing infants with DS to neuro-typical infants of a similar non-verbal mental ability, we were able to reveal potential strengths and weaknesses in the early language phenotype for individuals with DS. This has both theoretical and clinical implications.

\subsection{Theoretical and clinical implications}

From a theoretical perspective, by taking a development approach and by accounting for development in other aspects of cognition (not exclusively focusing on language), we were able to characterise the earliest stages of language development in infants with Down syndrome and show that there may be an early receptive language advantage. In addition, the onset of expressive language (in terms of productive expressive vocabulary and expressive communication) at this initial stage of acquisition seems to be as expected for the level of non-verbal mental ability. However, our study also shows that non-verbal abilities in infants with DS may have a delayed onset and pace of development compared to neuro-typical 
infants. This has also been shown in other studies of cognitive development of young children with DS studied longitudinally at 12 and 30 months showing that infants with Down syndrome make fewer gains in overall cognitive skills than children with other neurodevelopmental disorders matched on mental age (Fidler, Most, Booth-LaForce \& Kelly, 2008). Although these delays may appear small at this early point in development, we know that small differences in developmental timing (in this case of the acquisition of general cognitive skills) can impact on language development over time and result in more obvious deficits in phenotypic outcomes (Annaz, Karmiloff-Smith \& Thomas, 2008). When the onset of development of a particular skill is delayed and not in line with the typical developmental timing, there may be cascading effects later on (Marsten \& Cicchetti, 2010). Existing research suggests that non-verbal mental abilities/general cognitive skills are related to, and can account for, language development (Casby, 1992). For example, research in behavioural genetics has shown that timing plays a critical role in regulating gene-environment interactions and, consequently, in determining developmental outcomes (Lenroot \& Giedd, 2011 cited in Levy \& Eilam, 2013). In our study, the children with DS started to produce their first words on average 10 months later than their neuro-typical counterparts. This may be a small difference in relation to the human life span, but this initial delay can, over time, lead to a significant deviation from typical expressive language, and possibly to what may look like an isolated "domain specific" impairment in expressive language later in development. Future research should focus on considering how small variations in the early stages of development can develop into domains of relative strengths and weaknesses (Karmiloff-Smith, 1998).

From a clinical point of view, studying the developing phenotypes from its earliest origins is particularly relevant when considering early interventions, as there may be critical windows of opportunity in the early stages of development that could be targeted before they 
627

628

629

630

631

632

633

634

635

636

637

638

639

640

641

642

643

644

645

646

647

648

649

become areas of significant weakness, or areas of early strength may be identified through

which targeted intervention can be channelled. Currently there are few published intervention studies for young infants with Down syndrome. Having in depth knowledge of the how language progresses in the first 2-3 years of life can open opportunities for clinicians to develop ways of optimising language outcomes from the earliest stages of development.

Acknowledgments: The research study was funded by the ESRC and Down Syndrome Education International. We would also like to thank all the participants and their parents/carers for their time and continuous support.

\section{References}

Abbeduto, L., Warren, S. F., \& Conners, F. A. (2007). Language development in Down syndrome: from the prelinguistic period to the acquisition of literacy. Mental Retardation and Developmental Disabilities Research Reviews, 13, 247-261.

Annaz, D., Karmiloff-Smith, A., \& Thomas, M. S. (2008). The importance of tracing developmental trajectories for clinical child neuropsychology. Child Neuropsychology: Concepts, theory and practice, 7.

Cardoso-Martins, C., Mervis, C. B., \& Mervis, C. A. (1985). Early vocabulary acquisition by children with Down syndrome. American Journal of Mental Deficiency. 90(2), 177184

Casby, M.W. (1992). The Cognitive hypothesis and its influence on speech-language services in schools. Language, Speech, and Hearing Services in Schools, 23(3), 198-202

Caselli, M. C., Bates, E., Casadio, P., Fenson, J., Fenson, L., Sanderl, L., \& Weir, J. (1995). A cross-linguistic study of early lexical development. Cognitive Development, 10 (2), 159-199. 
Caselli, M. C., Vicari, S., Longobardi, E., Lami, L., PIzzoli,C., \& Stella, G. (1998). Gestures and words in early development of children with Down syndrome. Journal of Speech, Language, and Hearing Research, 41,1125-1135.

Chapman, R. S., Hesketh, L. J., \& Kistler, D. J. (2002). Predicting longitudinal change in language production and comprehension in individuals with Down syndrome: Hierarchical linear modelling. Journal of Speech, Language, and Hearing Research, 45(5), 902-915.

Chapman R.S., Seung, H.K., Schwartz, S.E.,\& Kay-Raining Bird, E. (1998). Language skills of children and adolescents with Down syndrome II. Production deficits. Journal of Speech, Language, and Hearing Research, 41, 861-873.

Chapman, R. S., \& Hesketh, L. J. (2000). Behavioural phenotype of individuals with Down syndrome. Mental Retardation and Developmental Disabilities Research Reviews, 6, 84-95.

Cuskelly, M., Povey, J., \& Jobling, A. (2016). Trajectories of development of receptive vocabulary in individuals with Down syndrome. Journal of Policy and Practice in Intellectual Disabilities, 13(2), 111-119.

D'Souza, D., D'Souza, H, \& Karmiloff-Smith, A. (2017). Precursors to language development in typically and atypically developing infants and toddlers: the importance of embracing complexity. Journal of Child Language, 44(3), 591-627.

Epstein, C. J. (1986). The consequences of chromosome imbalance. New York: Cambridge University Press.

Galeote, M., Sebastián, E., Checa, E., Rey, R., \& Soto, P. (2011). The development of vocabulary in Spanish children with Down syndrome: Comprehension, production, and gestures. Journal of Intellectual and Developmental Disability, 36(3), 184-196. 
674 Hamilton, A., Plunkett, K., \& Schafer, G. (2000) Infant vocabulary development assessed

675

676

677

678

679

680

681

682

683

684

685

686

687

688

689

690

691

692

693

694

695

696

697 with a British communicative development inventory. Journal of Child Language, 27 (3), 689-705

Karmiloff-Smith, A. (1998). Development itself is the key to understanding developmental disorders. Trends in Cognitive Sciences, 2, 389-398.

Karmiloff-Smith, A. (2009). Nativism versus constructivism: Rethinking the study of developmental disorders. Journal of Child Language, 45 (1), 56-63

Klein, P.B., \& Mervis, C.B. (1999). Contrasting patterns of cognitive abilities of 9- and 10year-olds with Williams syndrome or Down syndrome. Developmental Neuropsychology, 16 (2), 177-196

Kover, S. T., \& Atwood, A. K. (2013). Establishing equivalence: methodological progress in group-matching design and analysis. American Journal on Intellectual and Developmental Disabilities, 118(1), 3-15.

Lenroot, R. K., \& Giedd, J. N. (2011). Annual research review: Developmental considerations of gene by environment interactions. Journal of Child Psychology and Psychiatry, 52 (4), 429-441.

Levy, Y., \& Eilam, A. (2013). Pathways to language: a naturalistic study of children with Williams syndrome and children with Down syndrome. Journal of Child Language, 40, 106-138.

Martin, G. E., Klusek, J., Estigarribia, B., \& Roberts, J. E. (2009). Language characteristics of individuals with Down syndrome. Topics in Language Disorders, 29, 112-132.

Mason-Apps, E., Stojanovik, V., Houston-Price, C., \& Buckley, S. (2018). Longitudinal predictors of early language in infants with Down syndrome: A preliminary study. Research in Developmental Disabilities, 81, 37-51. 
Masten, A. S., \& Cicchetti, D. (2010). Developmental cascades. Development and Psychopathology, 22, 491-495.

Mervis, C. B., \& Robinson, B. F. (2003). Methodological issues in cross-group comparisons of language and/or cognitive development. In Y. Levy \& J. Schaeffer (Eds.), Language competence across populations: Toward a definition of specific language impairment (pp. 233-258). Mahwah, NJ: Lawrence Erlbaum.

Miller, J. F. (1999). Profiles of language development in children with Down syndrome. In J. Miller, M. Leddy, \& L. A. Leavitt (Eds.), Improving the communication of people with Down syndrome (pp. 11-40). Baltimore: Brookes Publishing

Mullen, E. M. (1995). Mullen scales of early learning (AGS ed.). San Antonio, TX: Pearson.

Næss, K. A. B., Lyster, S. A. H., Hulme, C., \& Melby-Lervåg, M. (2011). Language and verbal short-term memory skills in children with Down syndrome: A meta-analytic review. Research in Developmental Disabilities, 32(6), 2225-2234.

Oliver, B., \& Buckley, S. (1994). The language development of children with Down syndrome: First words to two-word phrases. Down Syndrome Research and Practice, 2(2), 71-75.

Parker, S. E., Mai, C. T., Canfield, M. A., Rickard, R., Wang, Y., Meyer, R. E et al., (2010). Updated national birth prevalence estimates for selected birth defects in the United States, 2004-2006. Birth Defects Research Part A: Clinical and Molecular Teratology, 88(12), 1008-1016.

Piaggio, G., Elbourne, D.R., Altman, D.G., Pocock, S.J., \& Evans, S.W., (2006). Reporting of noninferiority and equivalence randomized trials: An extension of the consort statement. Journal of the American Medical Association, 295(10), 1152-1160. 
Roberts, J. E., Price, J., \& Malkin, C. (2007). Language and communication development in Down syndrome. Mental Retardation and Developmental Disabilities Research Reviews,13(1), 26-35.

Rubin, D.B. (2001). Using Propensity Scores to Help Design Observational Studies: Application to the Tobacco Litigation. Health Services and Outcomes Research Methodology, 2(3), 169-188.

Schlichting, J. E. P. T., \& Lutje Spelberg, H. C. (2002). Lexilijst nederlands. Een instrument om de taalontwikkeling te onderzoeken bij nederlandstalige kinderen van 15-27 maanden in het kader van vroegtijdige onderkenning. Amsterdam: Pearson Assessment and Information B.V.

Seager, E., Mason-Apps, E., Stojanovik, V., Norbury, C., Bozicevic, L., \& Murray, L. (2018). How do maternal interaction style and joint attention relate to language development in infants with Down syndrome and typically developing infants?. Research in Developmental Disabilities, 83, 194-205.

Stoel-Gammon, C. (2001). Down syndrome phonology: Developmental patterns and intervention strategies. Down Syndrome Research and Practice, 7, 93-100.

Te Kaat-van den Os, D. T., Volman, C., Jongmans, M., \& Lauteslager, P. (2017). Expressive vocabulary development in children with Down Syndrome: A longitudinal study. Journal of Policy and Practice in Intellectual Disabilities, 14(4), 311-318.

Tomasello, M. (2003). Constructing a language: A usage-based theory of language acquisition. Cambridge: Havard University Press.

Van Herwegen, J., Smith, T., \&Dimitriou, D. (2015) Exploring different explanations for performance on a theory of mind task in Williams syndrome and Autism using eye movements. Research in Developmental Disabilities, 45-46, pp. 202-209 
745 Zampini, L., \& D'Odorico, L. (2013). Vocabulary development in children with Down syndrome: Longitudinal and cross-sectional data. Journal of Intellectual and Developmental Disability, 38(4), 310-317

748 Zimmerman, I. L., Steiner, V. G., \& Pond, R. E. (2002). Preschool Language Scales (4 ${ }^{\text {th }}$ ed.). San Antonio, TX: The Psychological Corporation 